\title{
Microtensile bond strength of root canal dentin treated with adhesive and fiber-reinforced post systems
}

\author{
Güvenç BAŞARAN(a) \\ Emine GÖNCÜ BAŞARAN(b) ID \\ Emrah AYNA ${ }^{(b)}$ \\ Yalçın DEĞER ${ }^{(b)}$ \\ Buket AYNA(c) iD \\ Mehmet Cudi TUNCER ${ }^{(d)}$ \\ (a) Dicle University, Faculty of Dentistry, \\ Department of Orthodontics, \\ Diyarbakır, Turkey. \\ (b) Dicle University, Faculty of Dentistry, \\ Department of Prosthodontics, \\ Diyarbakır, Turkey. \\ (c)Dicle University, Faculty of Dentistry, \\ Department of Pedodontics, \\ Diyarbakır, Turkey. \\ (d)Dicle University, Faculty of medical Science, \\ Department of Anatomy, Diyarbakır, Turkey.
}

Declaration of Interests: The authors certify that they have no commercial or associative interest that represents a conflict of interest in connection with the manuscript.

Corresponding Author:

Mehmet Cudi Tuncer

E-mail:drcudi@hotmail.com

htrps://doi.org/10.1590/1807-3107bor-2019.vol33.0027

Submitted: November 29, 2018

Accepted for publication: December 20, 2018

Last revision: March 01, 2019

\begin{abstract}
Nowadays, demand for esthetic restorations has risen considerably; thus, nonmetal esthetic posts made of either highstrength ceramics or reinforced resins, such as fiber-reinforced resin posts, have become more and more popular. Important characteristics of fiber-reinforced posts involve a modulus of elasticity similar to dentin and their ability to be cemented by an adhesive technique. A total of 36 maxillary incisors were divided into four groups. In this study, four adhesively luted fiber-reinforced (glass fiber, quartz glass fiber, zirconia glass fiber and woven polyethylene fiber ribbon) post systems were used. Post spaces were prepared by employing drills according to the protocol established for each group, and each post was adhesively luted with one of three adhesive systems. Three segments per root apical to the cementoenamel junction (CEJ) were obtained by sectioning the root under distilled water with a carbon spare saw. The samples (total of 108 sections) were $2.0 \pm 0.1 \mathrm{~mm}$ in thickness and they were stored individually in black film canisters with sterile distilled water. In order to determine the bond strength, the bonding area of each specimen was measured, and specimens were attached to a device to test microtensile strength at a speed of $1 \mathrm{~mm} / \mathrm{min}$. The analyses revealed no statistically significant differences between the adhesive systems and fiber-reinforced posts. ( $\mathrm{P}>0.05$ ). However, the coronal portion of the root dentin had the highest bond strength. Adhesive systems used along with fiber-reinforced resin posts demonstrated reliable bonding.
\end{abstract}

Keywords: Tooth Components; Dentin; Dental Enamel; Dental Cementum; Humans.

\section{Introduction}

Prefabricated posts are used to improve retention of core foundation materials in endodontically treated teeth when minimally remaining coronal dentin exists. Over the past decade, the use of fiber-reinforced resin posts (fiber posts) to restore endodontically treated teeth has become popular. ${ }^{1}$ The success rate of fiber posts has ranged from 48 to $100 \%$ over the years. ${ }^{2}$ Fiber posts include a similar elasticity modulus to dentin and also have high esthetic property. ${ }^{3}$ Another important quality is their ability to be cemented through an adhesive technique. ${ }^{4,5}$ Most fiber posts consist 
of a resin matrix with reinforcing quartz, glass, or woven polyethylene fiber. ${ }^{1}$ Esthetic fiber posts can be bonded with polymer dentin-bonding agents and resin cements within root canal spaces. This combined system transmits stress between the post and the root structure, reducing stress concentration and preventing fracture. $., 7,8,9,10$

It has been shown that debonding of the post is the main reason for failure of adhesively luted fiber posts. ${ }^{11,12}$ Several other factors may affect the bond strength of posts to dentin, including type of dentin, ${ }^{13}$ region of the dentin,,${ }^{14,15}$ different post surface pretreatment techniques, and type of adhesive and luting agents. ${ }^{6,16,17,18,19}$ Nowadays, various luting agents and corresponding adhesive systems are available for bonding fiber posts to the root canal dentin. Adhesive systems vary from multi-step etch-and-rinse systems to one-bottle self-etch non-rinse systems. The eventual type combines etchant, primer, and adhesive into one bottle, such as acidic monomers and acetone/ethanol as solvents in the same bottle. ${ }^{20,21,22}$

The bonding effectiveness among dentin, resin cement, and post can be assessed through pull-out tests or microtensile bond strength tests. ${ }^{10,23,24,25,26,27,28,29}$ The microtensile test was developed to overcome some of the limitations of other traditional bonding tests, such as shear and tensile tests. ${ }^{18}$ The microtensile test allows performing bond strength studies in specific areas of dental structures. ${ }^{30}$

The main objective of this study is to evaluate the bond strengths of four adhesively luted fiber post systems: glass fiber, quartz glass fiber, zirconia glass fiber, and woven polyethylene fiber ribbon, through the use of three adhesive systems in three portions of the root dentin: coronal, middle, and apical thirds. The null hypothesis was that no statistically significant difference in bond strength values would be found among root portions for neither fiber posts nor adhesive systems.

\section{Methodology}

\section{Patient follow up}

Thirty-six human maxillary central incisors extracted freshly for periodontal reasons were endodontically treated and divided into four groups $(n=9)$. The crown of each tooth was removed $2 \mathrm{~mm}$ coronal to the cementoenamel junction (CEJ) with a 0.15 diamond wafering blade (Buehler, Lake Bluff, USA) in an Isomet saw (IsoMet, Buehler, USA). In this study, four fiber-reinforced post systems and three adhesive systems were used. Brand names, manufacturers, batch numbers, compositions, and application procedures are shown in Table 1. The study protocol was approved by the Research Ethics Committee of our Dental Faculty Hospital (Protocol number: 2018/32).

\section{Post preparation}

In this study, three types of preshaped posts (1.6 $\mathrm{mm}$ in diameter) and one custom-shaped post were evaluated: zirconia-glass post (Snowpost, carbotech-

Table 1. Description of materials used in this study and information on the manufacturers.

\begin{tabular}{|c|c|c|c|}
\hline Product & Material type & Manufacturer & Batch numbers \\
\hline Snow post & Zirconia-glass fiber & Carbotech, Ganges, France & \#622440 \\
\hline D.T. light-post & Quartz-glass fiber & Bisco, Schaumburg, III & \# 1000000851 \\
\hline Cytec blanco & Glass fiber & Hahnenkratt, Königsbach-Stein, Germany & \#17186 \\
\hline Ribbond & Polyethylene fiber & Ribbond Inc., Seattle, Wash, & \#9578 \\
\hline Light-core & $\begin{array}{l}\text { Light-polymerizing core foundation } \\
\text { composite resin }\end{array}$ & Bisco, Schaumburg, III & \#0500009822 \\
\hline Duo-Link & Dual-polymerizing resin luting agent & Bisco, Schaumburg, III & \#0600004449 \\
\hline All bond 2 & Three-stage total-etch adhesive & Bisco, Schaumburg, III & \#0600011600 \\
\hline I bond & One-stage self-etch adhesive & Heraeus Kulzer, Hanau, Germany & \#66008943 \\
\hline One step plus & Two-stage total-etch adhesive & Bisco, Schaumburg, III & \#060000034 1 \\
\hline
\end{tabular}


Ganges, France), quartz-glass post (DT Light post, Bisco Inc, Schaumburg, USA), glass fiber post (Cytec blanco, Hahnenkratt, köningsbach-stein, Germany) and woven resin-supported polyethylene fiber ribbon post (Ribbond, Ribbond Inc, Seattle, USA). Each post was bonded with one of the following three systems: a one-stage self etch (I Bond; Hareaus Kulzer, Hanau, Germany), a two-stage total etch (One Step Plus, Bisco), and three-stage total etch adhesive (All Bond 2; Bisco).

Post spaces were prepared to a depth of $10 \mathrm{~mm}$ with drills supplied with each system. A dual-polymerizing resin luting agent (Duo-Link; Bisco) was mixed for 20 seconds and then placed in the post spaces with a

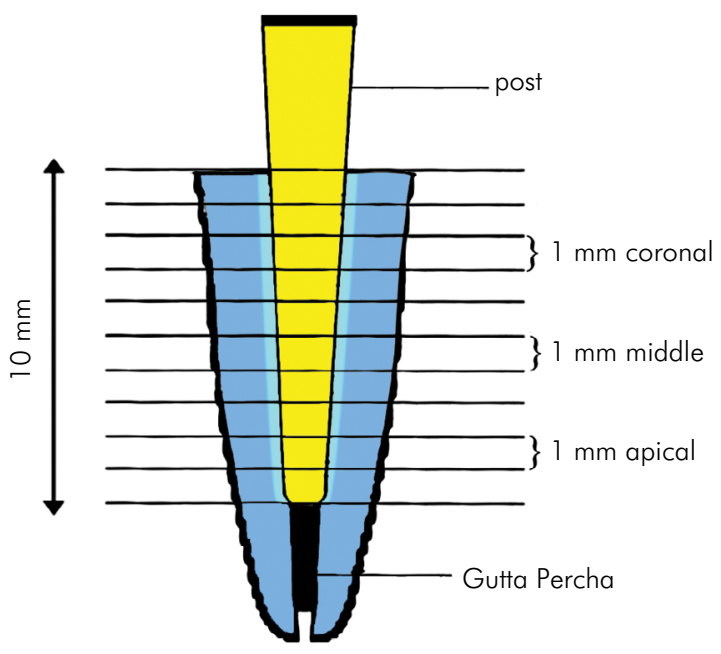

Figure 1. Schematic view of specimen preparation for the tensile test.
Lentulo spiral instrument (Maillefer Dentsply; Tulsa, USA). The posts were coated with cement and slowly seated with slight finger pressure. Excess cement was removed with an explorer (MSC-SD-414-R; Muzamal Surgical Co, Sialkat, Pakistan). The light source was placed directly on the flat coronal tooth surfaces, and the cement was polymerized for 40 seconds at 350 mW/cm2 (Hilux 350; First Medica, Greensboro, $\mathrm{NC}$ ). All specimens were prepared to receive composite resin core buildups (LightCore; Bisco) and were stored at $37^{\circ} \mathrm{C}$ for one week.

\section{Root sections}

Three segments per root apical to the CEJ were obtained by sectioning the root under distilled water coolant with an Isomet butcher saw. The sections were $1.0 \pm 0.1 \mathrm{~mm}$ in thickness. This procedure was performed in three serial slices per root, identified as coronal 1, 2, 3, middle 1, 2,3, and apical 1, 2, 3 (Figures 1 and 2). The thickness of each slice was measured with a digital caliper (Mitutoyo, Tokyo, Japan). Each slice was further trimmed with a diamond bur (Diamond flat end cylinder \#835; Coltene/Whaledent KG, Langenau, Germany) mounted in a high-speed handpiece under water cooling. This procedure was performed under a stereomicroscope (20X magnification) until the bur touched the post.

\section{Test procedure}

The trimmed specimens were glued onto a microtensile bond strength testing device (Microtensile

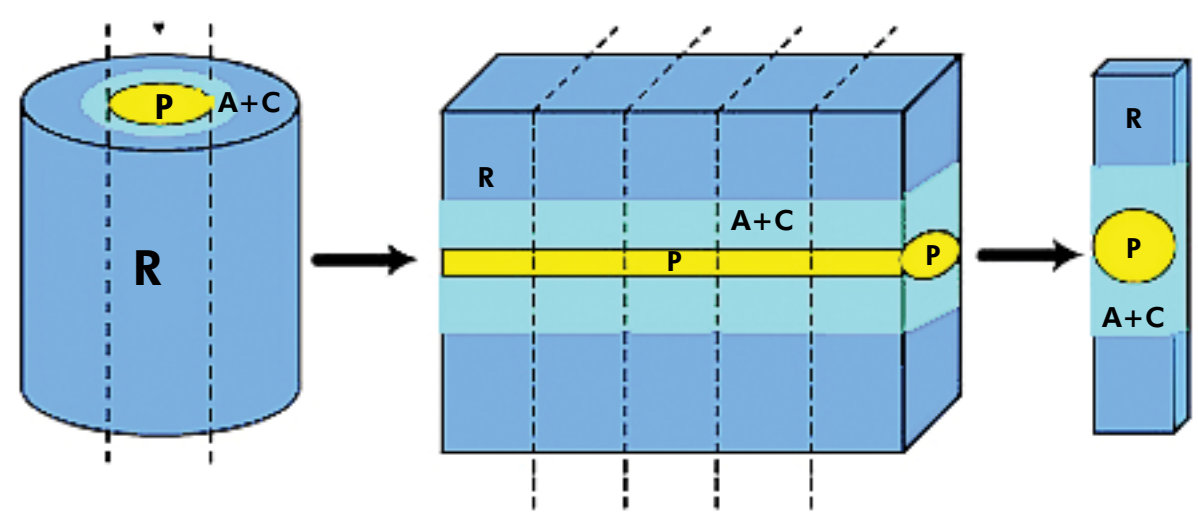

Figure 2. Schematic view of sample preparation in fiber post groups. R: Root, P: Post, A+C: Adhesive and Cement. 
Tester, Bisco; Schaumburg, USA), using cyanoacrylate glue (Zapit, Dental Ventures of America; Corona, USA) and subjected to tensile strength loaded at a crosshead speed of $1 \mathrm{~mm} / \mathrm{min})$. Since the bonded interface was curved, its area was measured by using a mathematical formula described earlier by Mallman et al. ${ }^{29}$ for similar purposes.

Failure loads were recorded in $\mathrm{N}$, and microtensile bond strength was measured in $\mathrm{MPa}$ as follows:

$$
\mu \mathrm{TBS}=\mathrm{F} / 1 / 2 \mathrm{C} \times \mathrm{T}
$$

where $\mathrm{F}$ is the force at failure, $\mathrm{C}$ is the circumference of the post ( $=2 \pi R[\pi=3.14, R=$ radius of the post $]$ ), and $T$ is the thickness of the rod.

\section{Results}

The data were analyzed with one-way ANOVA and Tukey's HSD tests at a significance level of $\mathrm{p}<0.05$ using SPSS 14.0 (Statistical Package for Social Sciences, SPSS Inc., Chicago, USA). There were no statistically significant differences in mean bond strengths (MPa) between fiber post and adhesive systems at $p>0.05$. The mean bond strengths of fiber posts and adhesive systems are shown in Table 2. For the "root portion" variable, the coronal third had significantly higher bond strength than the apical third $(p<0.007)$. The middle third was not significantly different from the coronal third $(\mathrm{p}>0.12)$ or from the apical third. Statistical results are shown in Table 3.

\section{Discussion}

This study was carried out to compare the performance of four different fiber posts and three different adhesive systems. The null hypothesis was rejected. The coronal portion of the root dentin showed significantly higher bond strength values.

In previous studies, researchers have investigated different root sections. Mallman et al. ${ }^{29}$ divided roots into 12 segments and evaluated 480 samples; Kalkan et al. ${ }^{10}$ divided them into 6 segments and evaluated 360 samples; and Zaitter et al. ${ }^{31}$ evaluated 144 samples. In this study, 324 samples were evaluated. Several studies have shown that retention is a relevant problem with intraradicular posts. ${ }^{29,32}$ One of the main reasons for failure is the poor adhesion between the fiber post and resin systems. ${ }^{33}$ Fiber post debonding from the root canal occurred due to poor retention. Failures may begin at the cement-dentin or cement-post interface. It is important to provide higher bond strength at these interfaces. The use of adhesive systems, resin cements, and surface conditioning agents is widespread, and it is important to analyze their relative performance. . $^{11,34,35}$

Several studies have been previously carried out to investigate the bond strength of adhesive and fiber post systems. ${ }^{36,37,38,39,40}$ Flexural strength of the fiber post may play a significant role in the outcome of postretained restoration. ${ }^{41}$ An important factor for fiber post strength could be the type of resinous matrix and the manufacturing process used to promote chemical bond between the fiber and the resin. ${ }^{42}$

The type of bond strength test used influences directly the results obtained. ${ }^{34}$ The method used to test post retention in this study, i.e., the microtensile bond strength test, was performed according to earlier studies, which have suggested it as a standard test for bond strength testing in small surface areas, ${ }^{18,43}$ and providing an understanding of bonding quality of root canals. ${ }^{18}$

Previous studies have reported that influential factors on microtensile strength are the type of composite, water storage, fiber post surface treatment, aging, and application of adhesive bonding. ${ }^{44,45}$ In a study carried out earlier, the bond strength of two adhesives (etch-and-rinse and self-etching) used with a resin cement and fiber posts was compared with one another; the resulting value was reported to be higher for the etch-and-rinse adhesive. ${ }^{46}$ Nonetheless, it has also been reported that the bonding mechanism to the root canal dentin is not influenced by the type of fiber-reinforced composite resin post. Similarly, Perdigão et al. ${ }^{19}$ pointed out that there were no significant differences in terms of bond strength between fiber posts cemented with the resin adhesive system provided by the respective manufacturer. According to another study, the selection of the fiber post seemed to be more important for high bond strength with respect to the type of luting material. ${ }^{47}$ 
Table 2. Mean bond strengths (Mpa) of fiber post and adhesive systems.

\begin{tabular}{|c|c|c|c|c|c|c|c|c|c|c|c|c|}
\hline \multirow{2}{*}{$\mathrm{MPa}$} & \multicolumn{3}{|c|}{ A } & \multicolumn{3}{|c|}{ B } & \multicolumn{3}{|c|}{ C } & \multicolumn{3}{|c|}{ D } \\
\hline & 1 & 2 & 3 & 1 & 2 & 3 & 1 & 2 & 3 & 1 & 2 & 3 \\
\hline \multirow{9}{*}{ Apical } & 4.2 & 4.1 & 3.7 & 5.1 & 4.0 & 3.7 & 3.2 & 3.7 & 4.1 & 3.5 & 4.8 & 4.8 \\
\hline & 3.3 & 4.3 & 3.8 & 5.0 & 4.0 & 3.8 & 3.0 & 4.1 & 4.3 & 3.7 & 4.9 & 5.2 \\
\hline & 3.7 & 3.9 & 3.9 & 5.2 & 4.2 & 3.2 & 4.0 & 3.9 & 4.5 & 3.9 & 4.8 & 3.9 \\
\hline & 3.6 & 3.8 & 3.8 & 5.2 & 5.1 & 3.1 & 4.1 & 4.2 & 4.7 & 3.8 & 4.7 & 3.9 \\
\hline & 3.6 & 4.1 & 3.6 & 5.1 & 4.0 & 3.8 & 3.9 & 3.8 & 4.4 & 3.9 & 4.8 & 4.7 \\
\hline & 3.6 & 4.1 & 3.8 & 5.0 & 3.9 & 3.8 & 4.0 & 3.9 & 5.6 & 3.8 & 4.9 & 4.6 \\
\hline & 3.7 & 3.9 & 3.9 & 5.2 & 4.0 & 4.6 & 3.9 & 4.0 & 6.1 & 4.1 & 4.8 & 4.7 \\
\hline & 3.8 & 4.0 & 3.8 & 5.1 & 4.2 & 2.9 & 5.1 & 3.9 & 3.2 & 3.9 & 4.9 & 4.9 \\
\hline & 3.4 & 4.2 & 3.7 & 5.3 & 4.1 & 2.8 & 3.9 & 3.9 & 4.1 & 4.8 & 4.7 & 4.8 \\
\hline \multirow{9}{*}{ Middle } & 6.1 & 4.8 & 5.1 & 7.1 & 5.4 & 2.6 & 5.2 & 5.8 & 4.8 & 5.9 & 6.5 & 5.4 \\
\hline & 5.9 & 4.4 & 5.4 & 6.9 & 5.8 & 4.9 & 5.9 & 5.5 & 5.2 & 5.3 & 6.8 & 5.5 \\
\hline & 6.1 & 5.1 & 5.4 & 7.1 & 6.0 & 4.7 & 5.6 & 5.7 & 5.2 & 5.5 & 6.7 & 5.7 \\
\hline & 6.0 & 3.8 & 5.3 & 7.8 & 6.1 & 4.5 & 5.6 & 5.4 & 5.1 & 5.5 & 6.1 & 5.4 \\
\hline & 6.2 & 4.3 & 5.2 & 7.6 & 6.0 & 4.0 & 5.1 & 5.6 & 4.9 & 5.3 & 6.1 & 5.6 \\
\hline & 5.9 & 4.9 & 5.5 & 6.9 & 5.9 & 4.9 & 4.9 & 5.0 & 5.7 & 5.4 & 6.3 & 5.3 \\
\hline & 6.0 & 4.6 & 5.9 & 7.5 & 5.6 & 4.2 & 6.2 & 5.2 & 5.9 & 5.6 & 6.8 & 5.5 \\
\hline & 6.1 & 5.9 & 6.3 & 7.3 & 7.3 & 3.8 & 4.8 & 5.0 & 5.9 & 4.8 & 6.7 & 5.4 \\
\hline & 6.0 & 3.8 & 6.2 & 7.1 & 7.2 & 5.4 & 4.9 & 5.9 & 5.0 & 5.1 & 6.9 & 6.3 \\
\hline \multirow{9}{*}{ Coronal } & 9.8 & 7.8 & 8.2 & 9.7 & 8.8 & 8.8 & 9.3 & 8.0 & 8.9 & 8.1 & 8.6 & 8.1 \\
\hline & 9.8 & 7.9 & 8.1 & 9.5 & 7.9 & 7.5 & 8.2 & 8.1 & 8.7 & 8.9 & 8.7 & 9.3 \\
\hline & 8.4 & 7.9 & 8.0 & 9.6 & 8.7 & 8.6 & 8.1 & 7.0 & 6.9 & 8.0 & 8.8 & 7.4 \\
\hline & 8.5 & 6.7 & 8.1 & 8.6 & 8.7 & 8.8 & 9.4 & 8.2 & 9.9 & 9.2 & 8.9 & 8.2 \\
\hline & 8.9 & 8.9 & 8.2 & 8.3 & 9.7 & 8.4 & 8.2 & 9.2 & 8.0 & 8.1 & 8.9 & 8.3 \\
\hline & 9.6 & 7.9 & 9.1 & 9.1 & 8.7 & 8.5 & 8.9 & 9.3 & 8.5 & 7.8 & 9.5 & 9.1 \\
\hline & 9.3 & 6.7 & 9.1 & 9.8 & 7.9 & 7.4 & 8.9 & 9.1 & 8.0 & 8.8 & 7.7 & 9.3 \\
\hline & 9.6 & 7.9 & 8.2 & 8.6 & 8.8 & 9.3 & 8.1 & 8.3 & 8.8 & 7.9 & 8.5 & 9.1 \\
\hline & 9.8 & 8.8 & 8.1 & 9.6 & 6.7 & 8.6 & 7.9 & 7.4 & 9.1 & 8.3 & 8.0 & 8.4 \\
\hline
\end{tabular}

A: Snow post; B: Cytec Blanco; C: D.T. Light post; D: Ribbond; 1: I bond bonding system; 2: All bond 2 bonding system; 3: One step plus bonding system.

In this study, we also assessed the bond strength at each section of the post. Since the post stabilizes and retains the core, it is crucial to determine its different levels of adhesion. The coronal portion of the canal is the closest part of the canal space, making it easier to etch and apply the adhesive agents more thoroughly than in deeper areas of the canal. Furthermore, light curing has also proven to be more effective. A previous study has shown that the number of dentinal tubules diminishes and moves from the crown to the root apex..$^{48}$ There is low infiltration of adhesive into the tubules at the apical third for light-curing adhesives. ${ }^{5,8,48}$

Ferrari and Mannocci reported that resin tag density is higher in the coronal portion than that at the middle and apical thirds. ${ }^{49}$ Furthermore, 
Table 3. Mean and standard deviations of the microtensile bond strength of the study groups.

\begin{tabular}{|c|c|c|c|}
\hline \multicolumn{3}{|c|}{ Groups } & \multirow{2}{*}{$\begin{array}{l}\text { Mean } \pm \text { So } \\
3.65 \pm 1.09\end{array}$} \\
\hline \multirow{9}{*}{ A } & \multirow{3}{*}{1} & Apical & \\
\hline & & Middle & $6.03 \pm 2.04$ \\
\hline & & Coronal & $9.3 \pm 3.80$ \\
\hline & \multirow{3}{*}{2} & Apical & $4.04 \pm 1.87$ \\
\hline & & Middle & $4.63 \pm 2.12$ \\
\hline & & Coronal & $7.83 \pm 2.98$ \\
\hline & \multirow{3}{*}{3} & Apical & $3.85 \pm 1.43$ \\
\hline & & Middle & $5.47 \pm 1.99$ \\
\hline & & Coronal & $8.24 \pm 3.37$ \\
\hline \multirow{9}{*}{ B } & \multirow{3}{*}{1} & Apical & $5.23 \pm 1.88$ \\
\hline & & Middle & $7.25 \pm 2.01$ \\
\hline & & Coronal & $9.2 \pm 2.78$ \\
\hline & \multirow{3}{*}{2} & Apical & $4.85 \pm 1.53$ \\
\hline & & Middle & $6.14 \pm 2.01$ \\
\hline & & Coronal & $8.43 \pm 1.98$ \\
\hline & \multirow{3}{*}{3} & Apical & $3.94 \pm 1.90$ \\
\hline & & Middle & $4.43 \pm 1.89$ \\
\hline & & Coronal & $8.11 \pm 2.61$ \\
\hline \multirow{9}{*}{ C } & \multirow{3}{*}{1} & Apical & $4.02 \pm 0.98$ \\
\hline & & Middle & $5.35 \pm 1.41$ \\
\hline & & Coronal & $8.87 \pm 3.08$ \\
\hline & \multirow{3}{*}{2} & Apical & $3.98 \pm 1.02$ \\
\hline & & Middle & $5.46 \pm 1.63$ \\
\hline & & Coronal & $8.28 \pm 2.89$ \\
\hline & \multirow{3}{*}{3} & Apical & $4.55 \pm 1.18$ \\
\hline & & Middle & $5.30 \pm 2.01$ \\
\hline & & Coronal & $8.40 \pm 2.88$ \\
\hline \multirow{9}{*}{ D } & \multirow{3}{*}{1} & Apical & $3.94 \pm 0.65$ \\
\hline & & Middle & $5.37 \pm 1.31$ \\
\hline & & Coronal & $8.24 \pm 1.89$ \\
\hline & \multirow{3}{*}{2} & Apical & $4.81 \pm 1.19$ \\
\hline & & Middle & $6.54 \pm 1.88$ \\
\hline & & Coronal & $8.54 \pm 2.23$ \\
\hline & \multirow{3}{*}{3} & Apical & $4.22 \pm 1.11$ \\
\hline & & Middle & $5.56 \pm 2.98$ \\
\hline & & Coronal & $8.57 \pm 3.56$ \\
\hline
\end{tabular}

A: Snow post; B: Cytec Blanco; C: D.T. Light post; D: Ribbond; 1: I bond bonding system; 2: All bond 2 bonding system; 3: One step plus bonding system. in another study, higher bond strength values were obtained at the apical third. However, this result is much lower than the findings for the coronal portion obtained in other studies. ${ }^{29,49}$ In another study that assessed bond strength of light-curing and self-curing adhesives to different root dentin portions (coronal, middle, and apical) using a fiber post, significant differences were determined in bond strength values. ${ }^{50}$ The coronal portion showed significantly higher values in terms of mean bond strength than those obtained in the middle and apical regions. ${ }^{51}$

Mallmann et al. ${ }^{29}$ reported no significant differences in bond strength between the post and adhesive systems, but the bond strength of coronal portions was higher. Those findings reported in previous studies also support our findings. According to another study, adhesive systems achieved good bonding to root dentin and fiberreinforced composite resin posts, and there was no significant difference with respect to each other. ${ }^{28}$ Another study showed no significant differences when post types were compared by using section and adhesive type variables..$^{52}$

The specimens in the present study were not exposed to any mechanical or thermal fatigue. As it is known, thermocycling causes an important decrease in the flexural strength of fiber posts. In addition, mechanical fatigue enhances microleakage in all types of post; nevertheless, mechanical fatigue does not lead to any change in the bond strengths of fiber posts and light-polymerized adhesives when the cervical third of root dentin was bonded to a resin cement. ${ }^{29,53,54,55,56}$

\section{Conclusions}

Within the limitations of this study, the following conclusions were drawn:

a. The bonding mechanism to root canal dentin was not influenced by the type of fiber post.

b. The coronal portion of root dentin showed significantly higher bond strength values. However, there were no significant differences between the coronal-middle or middle-apical portions. 


\section{References}

1. Grandini S, Goracci C, Monticelli F, Tay FR, Ferrari M. Fatigue resistance and structural characteristics of fiber posts: three-point bending test and SEM evaluation. Dent Mater. 2005 Feb;21(2):75-82. https://doi.org/10.1016/i.dental.2004.02.012

2. Dikbas I, Tanalp J. An overview of clinical studies on fiber post systems. ScientificWorldJournal. 2013 Oct;2013:171380. https://doi.org/10.1155/2013/171380

3. Asmussen E, Peutzfeldt A, Heitmann T. Stiffness, elastic limit, and strength of newer types of endodontic posts. J Dent. 1999 May;27(4):275-8. https://doi.org/10.1016/S0300-5712(98)00066-9

4. Torbjörner A, Karlsson S, Odman PA. Survival rate and failure characteristics for two post designs. J Prosthet Dent. 1995 May;73(5):439-44. https://doi.org/10.1016/S0022-3913(05)80072-1

5. Vichi A, Grandini S, Davidson CL, Ferrari M. An SEM evaluation of several adhesive systems used for bonding fiber posts under clinical conditions. Dent Mater. 2002 Nov;18(7):495-502. https://doi.org/10.1016/S0109-5641(01)00065-3

6. Bitter K, Priehn K, Martus P, Kielbassa AM. In vitro evaluation of push-out bond strengths of various luting agents to tooth-colored posts. J Prosthet Dent. 2006 Apr;95(4):302-10. https://doi.org/10.1016/i.prosdent.2006.02.012

7. Braga NM, Paulino SM, Alfredo E, Sousa-Neto MD, Vansan LP. Removal resistance of glass-fiber and metallic cast posts with different lengths. J Oral Sci. 2006 Mar;48(1):15-20. https://doi.org/10.2334/josnusd.48.15

8. Ferrari M, Vichi A, Grandini S, Goracci C. Efficacy of a self-curing adhesive-resin cement system on luting glass-fiber posts into root canals: an SEM investigation. Int J Prosthodont. 2001 Nov-Dec;14(6):543-9.

9. Giachetti L, Scaminaci Russo D, Bertini F, Giuliani V. Translucent fiber post cementation using a light-curing adhesive/composite system: SEM analysis and pull-out test. J Dent. 2004 Nov;32(8):629-34. https://doi.org/10.1016/i.jdent.2004.06.004

10. Kalkan M, Usumez A, Ozturk AN, Belli S, Eskitascioglu G. Bond strength between root dentin and three glass-fiber post systems. J Prosthet Dent. 2006 Jul;96(1):41-6. https://doi.org/10.1016/i.prosdent.2006.05.005

11. Monticelli F, Grandini S, Goracci C, Ferrari M. Clinical behavior of translucent-fiber posts: a 2-year prospective study. Int J Prosthodont. 2003 Nov-Dec;16(6):593-6.

12. Ferrari M, Vichi A, García-Godoy F. Clinical evaluation of fiber-reinforced epoxy resin posts and cast post and cores. Am J Dent. 2000 May;13(Spec No):15B-8B.

13. Miör IA, Smith MR, Ferrari M, Mannocci F. The structure of dentine in the apical region of human teeth. Int Endod J. 2001 Jul;34(5):346-53. https://doi.org/10.1046/j.1365-2591.2001.00393.x

14. Marques de Melo R, Galhano G, Barbosa SH, Valandro LF, Pavanelli CA, Bottino MA. Effect of adhesive system type and tooth region on the bond strength to dentin. J Adhes Dent. 2008 Feb;10(2):127-33. http://dx.doi.org/10.3290/i.jad.a13331

15. Miyazaki M, Hinoura K, Saito H, Onose H, Moore BK. Influence of light irradiation of dentine primers on dentine-resin bond. J Dent. 1995 Dec;23(6):371-4. https://doi.org/10.1016/0300-5712(94)00020-G

16. Balbosh A, Kern M. Effect of surface treatment on retention of glass-fiber endodontic posts. J Prosthet Dent. 2006 Mar;95(3):218-23. https://doi.org/10.1016/i.prosdent.2006.01.006

17. Giachetti L, Scaminaci Russo D, Bertini F. [Use of light-curing composite and adhesive systems for the cementation of tranlucent fiber posts. SEM analysis and pull-out test]. Minerva Stomatol. 2003 Apr;52(4):133-44. Italian.

18. Pashley DH, Carvalho RM, Sano H, Nakajima M, Yoshiyama M, Shono Y, et al. The microtensile bond test: a review. J Adhes Dent. 1999;1(4):299-309.

19. Perdigão J, Geraldeli S, Lee IK. Push-out bond strengths of tooth-colored posts bonded with different adhesive systems. Am J Dent. 2004 Dec;17(6):422-6.

20. Perdigão J. New developments in dental adhesion. Dent Clin North Am. 2007 Apr;51(2):333-57. https://doi.org/10.1016/i.cden.2007.01.001

21. Van Meerbeek B, Perdigão J, Lambrechts P, Vanherle G. The clinical performance of adhesives. J Dent. 1998 Jan;26(1):1-20. https://doi.org/10.1016/S0300-5712(96)00070-X

22. Van Landuyt KL, Snauwaert J, De Munck J, Peumans M, Yoshida Y, Poitevin A, et al. Systematic review of the chemical composition of contemporary dental adhesives. Biomaterials. 2007 Sep;28(26):3757-85. https://doi.org/10.1016/j.biomaterials.2007.04.044

23. Aksornmuang J, Nakajima M, Foxton RM, Tagami J. Regional bond strengths of a dual-cure resin core material to translucent quartz fiber post. Am J Dent. 2006 Feb;19(1):51-5

24. Aksornmuang J, Foxton RM, Nakajima M, Tagami J. Microtensile bond strength of a dual-cure resin core material to glass and quartz fibre posts. J Dent. 2004 Aug;32(6):443-50. https://doi.org/10.1016/i.jdent.2004.03.001

25. Valandro LF, Yoshiga S, de Melo RM, Galhano GA, Mallmann A, Marinho CP, et al. Microtensile bond strength between a quartz fiber post and a resin cement: effect of post surface conditioning. J Adhes Dent. 2006 Apr;8(2):105-11. 
Microtensile bond strength of root canal dentin treated with adhesive and fiber-reinforced post systems

26. Goracci C, Raffaelli O, Monticelli F, Balleri B, Bertelli E, Ferrari M. The adhesion between prefabricated FRC posts and composite resin cores: microtensile bond strength with and without post-silanization. Dent Mater. 2005 May;21(5):437-44. https://doi.org/10.1016/j.dental.2004.07.012

27. Schmage P, Sohn J, Ozcan M, Nergiz I. Effect of surface treatment of titanium posts on the tensile bond strength. Dent Mater. 2006 Feb;22(2):189-94. https://doi.org/10.1016/i.dental.2005.04.015

28. Vano M, Goracci C, Monticelli F, Tognini F, Gabriele M, Tay FR, et al. The adhesion between fibre posts and composite resin cores: the evaluation of microtensile bond strength following various surface chemical treatments to posts. Int Endod J. 2006 Jan;39(1):31-9. https://doi.org/10.1111/j.1365-2591.2005.01044.x

29. Mallmann A, Jacques LB, Valandro LF, Muench A. Microtensile bond strength of photoactivated and autopolymerized adhesive systems to root dentin using translucent and opaque fiber-reinforced composite posts. J Prosthet Dent. 2007 Mar;97(3):165-72. https://doi.org/10.1016/i.prosdent.2007.01.008

30. Sano H, Shono T, Sonoda H, Takatsu T, Ciucchi B, Carvalho R, et al. Relationship between surface area for adhesion and tensile bond strength—evaluation of a micro-tensile bond test. Dent Mater. 1994 Jul;10(4):236-40. https://doi.org/10.1016/0109-5641(94)90067-1

31. Zaitter S, Sousa-Neto MD, Roperto RC, Silva-Sousa YT, El-Mowafy O. Microtensile bond strength of glass fiber posts cemented with self-adhesive and self-etching resin cements. J Adhes Dent. 2011 Feb;13(1):55-9.

32. Schwartz RS, Robbins JW. Post placement and restoration of endodontically treated teeth: a literature review. J Endod. 2004 May;30(5):289-301. https://doi.org/10.1097/00004770-200405000-00001

33. Daneshkazemi A, Davari A, Askari N, Kaveh M. Effect of different fiber post surface treatments on microtensile bond strength to composite resin. J Prosthet Dent. 2016 Dec;116(6):896-901. https://doi.org/10.1016/i.prosdent.2016.03.029

34. Malferrari S, Monaco C, Scotti R. Clinical evaluation of teeth restored with quartz fiber-reinforced epoxy resin posts. Int J Prosthodont. 2003 Jan-Feb;16(1):39-44.

35. Ferrari M, Cagidiaco MC, Goracci C, Vichi A, Mason PN, Radovic l, et al. Long-term retrospective study of the clinical performance of fiber posts. Am J Dent. 2007 Oct;20(5):287-91.

36. Silva MB, Tavarez RR, Assis FS, Tonetto MR, Porto TS, Bhandi SH, et al. The Effect of Self-adhesive and Self-etching Resin Cements on the Bond Strength of Nonmetallic Posts in Different Root Thirds. J Contemp Dent Pract. 2015 Feb;16(2):147-53. https://doi.org/10.5005/ip-journals-10024-1652

37. Irmak Ö, Yaman BC, Lee DY, Orhan EO, Mante FK, Ozer F. Flexural strength of fiber reinforced posts after mechanical aging by simulated chewing forces. J Mech Behav Biomed Mater. 2018 Jan;77:135-9. https://doi.org/10.1016/i.jmbbm.2017.09.001

38. Aksornmuang J, Chuenarrom C, Chittithaworn N. Effects of various etching protocols on the flexural properties and surface topography of fiber-reinforced composite dental posts. Dent Mater J. 2017 Sep;36(5):614-21. https://doi.org/10.4012/dmi.2016-290

39. Reis GR, Silva FP, Oliveira-Ogliari A, Faria-E-Silva AL, Moraes RR, Novais VR, et al. An experimental thermally deposited coating for improved bonding to glass-fiber posts. J Adhes Dent. 2017;19(1):49-57.

40. Zicari F, Coutinho E, Scotti R, Van Meerbeek B, Naert I. Mechanical properties and micro-morphology of fiber posts. Dent Mater. 2013 Apr;29(4):e45-52. https://doi.org/10.1016/i.dental.2012.11.001

41. Vallittu PK. Are we misusing fiber posts? Guest editorial. Dent Mater. 2016 Feb;32(2):125-6. https://doi.org/10.1016/i.dental.2015.11.001

42. Alonso de la Peña V, Darriba IL, Caserío Valea M, Guitián Rivera F. Mechanical properties related to the microstructure of seven different fiber reinforced composite posts. J Adv Prosthodont. 2016 Dec;8(6):433-8. https://doi.org/10.4047/jap.2016.8.6.433

43. Sudsangiam S, van Noort R. Do dentin bond strength tests serve a useful purpose? J Adhes Dent. 1999;1(1):57-67.

44. Prithviraj DR, Soni R, Ramaswamy S, Shruthi DP. Evaluation of the effect of different surface treatments on the retention of posts: a laboratory study. Indian J Dent Res. 2010 Apr-Jun;21(2):201-6. https://doi.org/10.4103/0970-9290.66637

45. Radovic I, Monticelli F, Papacchini F, Magni E, Cury AH, Vulicevic ZR, et al. Accelerated aging of adhesive-mediated fiber post-resin composite bonds: A modeling approach. J Dent. 2007 Aug;35(8):683-9. https://doi.org/10.1016/i.jdent.2007.05.006

46. Goracci C, Sadek FT, Fabianelli A, Tay FR, Ferrari M. Evaluation of the adhesion of fiber posts to intraradicular dentin. Oper Dent. 2005 Sep-Oct;30(5):627-35.

47. Kremeier K, Fasen L, Klaiber B, Hofmann N. Influence of endodontic post type (glass fiber, quartz fiber or gold) and luting material on push-out bond strength to dentin in vitro. Dent Mater. 2008 May;24(5):660-6. https://doi.org/10.1016/i.dental.2007.06.029

48. Carrigan PJ, Morse DR, Furst ML, Sinai IH. A scanning electron microscopic evaluation of human dentinal tubules according to age and location. J Endod. 1984 Aug;10(8):359-63. https://doi.org/10.1016/S0099-2399(84)80155-7

49. Ferrari M, Mannocci F. A 'one-bottle' adhesive system for bonding a fibre post into a root canal: an SEM evaluation of the post-resin interface. Int Endod J. 2000 Jul;33(4):397-400. https://doi.org/10.1046/i.1365-2591.2000.00310.x

50. Mallmann A, Jacques LB, Valandro LF, Mathias P, Muench A. Microtensile bond strength of light- and self-cured adhesive systems to intraradicular dentin using a translucent fiber post. Oper Dent. 2005 Jul-Aug;30(4):500-6. 
51. Inove S, Vargas MA, Abe Y, Yoshida Y, Lambrechts P, Vanherle G, et al. Microtensile bond strength of eleven contemporary adhesives to dentin. J Adhes Dent. 2001;3(3):237-45.

52. Başaran EG, Ayna E, Halifeoğlu M. Microleakage of endodontically treated teeth restored with 3 different adhesive systems and 4 different fiber-reinforced posts. J Prosthet Dent. 2012 Apr;107(4):239-51. https://doi.org/10.1016/S0022-3913(12)60069-9

53. Gaston BA, West LA, Liewehr FR, Fernandes C, Pashley DH. Evaluation of regional bond strength of resin cement to endodontic surfaces [doi]. J Endod. 2001 May;27(5):321-4. https://doi.org/10.1097/00004770-200105000-00001

54. Reid LC, Kazemi RB, Meiers JC. Effect of fatigue testing on core integrity and post microleakage of teeth restored with different post systems. J Endod. 2003 Feb;29(2):125-31. https://doi.org/10.1097/00004770-200302000-00010

55. Drummond JL, Toepke TR, King TJ. Thermal and cyclic loading of endodontic posts. Eur J Oral Sci. 1999 Jun;107(3):220-4. https://doi.org/10.1046/i.0909-8836.1999.eos1070310.x

56. Purton DG, Chandler NP, Qualtrough AJ. Effect of thermocycling on the retention of glass-fiber root canal posts. Quintessence Int. 2003 May;34(5):366-9. 